(Aus dem Hygienischen Institut der Universität Heidelberg [Direktor: Geh. Hofrat Prof. Dr. H. Kossel].)

\title{
Bakterientötende Kräfte im Serum von Gesunden und Kranken.
}

\author{
Von \\ E. G. Dresol und W. Koller.
}

In Studien zur unspezifischen Reiźtherapie über die experimentelle Steigerung der Anthracocidie im Blute haben Dresel und Freund ${ }^{1}$ ) nachgewiesen, daß das normalerweise nicht anthracocid wirkende menschliche Serum milzbrandfeindliche Kraft erlangen kann, ohne daß es sich um einen Immunisierungsprozeß, im gewöhnlichen Sinne handelt. Beim Kaninchen wurde festgestellt, daß im strömenden Blute eine Vermehrung der anthracociden Stoffe außer durch unspezifische Reiztherapie auch durch pathologische Zustände oder durch Schwangerschaft ausgelöst werden konnte.

Daher sollte gepriuft werden, wie sich menschliches Serum bei pathologischen Zuständen, während der Menstruation und bei Neugeborenen gegenüber Bakterien verhält. Im Anschlus an die vorige Mitteilung wurde in der Hauptsache das Verhalten gegenüber Milzbrandbacillen, in einer Reihe der Serumproben gleichzeitig gegen Milzbrand- und Typhusbacillen geprüft, weil Dresel und Freund zu dem Ergebnisse gekommen waren, daß die wirksamen Stoffe beim Menschen auch noch aus anderen Zellen, als den Blutplättchen stammen könnten; d. h. daß es sich nicht ausschließlich um Plakine handeln müsse.

\section{Versuchsanordnung.}

230 Sera von gesunden und kranken Mensehen wurden folgenderweise untersucht: Jedes niemals über 48 Stunden alte Serum wurde zu je $0,5 \mathrm{ccm}$ auf 4 Spitzgläschen verteilt. Von einer 24stündigen sporenfreien, sehr gut durchgeschüttelten Milzbrandbacillenbouillonkultur wurde mit Bouillon eine Verdünnung 1:1000 hergestellt und davon jedem Spitzgläschen aus gleichkalibrierter Pipette ein Tropfen zugesetzt. Das 1. Spitzgläschen wurde sofort durch Ausgießen zur Agarplatte verarbeitet, das 2 . nach 1 stündigem, das 3 . nach 4 stündigem und das 4. nach 6 stündigem Verweilen im Brutsehrank bei $37^{\circ}$. Als Kontrolle dienten zu jedem Versuch 4 Spitzgläschen, enthaltend $0,5 \mathrm{ccm}$ Bouillon und 1 Tropfen der Milzbrandverdünnung, die sofort, nach 1, 4 und 6 Stunden Verweilens im Brutschrank zu Agarplatten verarbeitet wurden. 
Nach 24stündigem Aufenthalt im Brutschrank wurden die aufgegangenen Kolonien gezühlt. Nach 48stündigem Aufenthalt im Brutschrank trat keine nennenswerte Vermehrung der Kolonien auf, so daß die Versuche stets nach 24 Stunden abgeschlossen werden konnten.

Der verwandte Milzbrandstamm, ein alter Sammlungsstamm des Hygienischen Instituts, zeichnete sich. von vornherein durch geringe Neigung zum Sporenbilden aus; außerdem ließen sich die Milzbrandfäden in der Bouillonkultur leicht durch Schütteln verteilen. Als nach $11 / 2$ jährigem Gebrauch bei fast täglichem Überimpfen der Stamm auf den Agarkontrollplatten nicht mehr ganz charakteristisch wuchs die Kolonien ließen die feinen' Randverschlingungen vermissen -, wurden eine Reihe Sera mit 4 weiteren verschiedenen Milzbrandstämmen geprüft. Davon waren 2 Stämme 1912 und 1914 aus Material von erkrankten Menschen gezüchtet, 2 stammten aus sibirischen Mähnen und indischem Ziegenhaar. Als alle. 5 Stämme gleichmäßig durch die Sera beeinflußt wurden, wurde für die letzten 100 Sera Stamm III aus sibirischen Mähnen benutzt. Auch er zeigt eine leichte Verzögerung in der Sporenbildung und ist für Mäuse pathogen. Der ursprüngliche Stamm I hat die Fähigkeit, Sporen zu bilden, ganz eingebüßt, und sie auch nach einer Mauspassage nicht wieder erlangt. Er tötete eine weiße Maus, die mit 1 Öse Agarkultur an der Schwanzwurzel geimpft war, nach 60 Stunden, und zwar noch, als er wegen seines uncharakteristischen Wachstums von den Untersuchungen ausgeschlossen war*).

Es sei noch erwähnt, daß alle zu den Versuchen benutzten Kochungen von Bouillon und Agar mit Pferdefleisch hergestellt waren und daß

*) In seiner Arbeit: Utber den Einfluß intravenöser Proteinkörperzufuhr auf die Bactericidie des Normalserums, kommt $O$. Pfeiler $^{2}$ ) zu dem Ergebnis, daB seine Beobachtungen über den Einfluß des Caseosans auf die milzbrandtötende Kraft des Kaninchenserums im Gegensatz zu den von Dresel und Freund mitgeteilten Befunden ständen. Dazu ist zu bemerken: 1. Unsere Mitteilungen beziehen sich nicht auf Kaninchenserum, das stets starke anthracocide Kräfte enthält, sondern auf die Steigerung der Anthracocidie im Plasma und im Frischllutextrakt bcim Kaninchen nach Caseosaninjektionen und anderen unspezifischen Reizen. Also schon aus diesem Grunde lassen sich die Ergebnisse üherhaupt nicht vergleichen. Dazu kommt noch 2., daß uns die von $O$. Pfeiler angewandte Versuchsanordnung bedenklich scheint. Seine Keimaussaatzahlen bewegen sich zwischen 85000 und 120000 Keimen im Kubikzentimeter Serum, während wir bei Milzbrandbacillen die Zahlen von 2000 Keimen in $1 / 2 \mathrm{ccm}$, also von 4000 in einem Kubikzentimeter Serum nicht überschritten. Es ist eine alte Erfahrung, daß bei bactericiden Versuchen sehr viel für die Ergebnisse von der Menge der Aussaat abhängt, da es sich um quantitative Verhältnisse handelt. Außerdem halten wir die von uns angewandte J'echnil des Plattengußverfahrens für solche Untersuchungen, bei denen es sich um die Auszählung von Keimen handelt, dem von Pfeiler angewandten Strichverfahren für überlegen. Daß bei der Verwendung durch Pfeiler der Milzbrandbacillenstamm ,Heidelberg“ für Mäuse nicht pathogen war, könnte eine Erklärung wohl nur in der Verschiedenheit der zur Züchtung verwandten Nährböden finden. Dresel und Freund. 
die Wasserstoffionenkonzentration mit dem Komparator nach $M i$ chaelis geprüft wurde, um gleiche Wachstumsbedingungen zu sichern. Die Milzbrandstämme zeigten sich nämlich gegen Schwankungen der Wasserstoffionenkonzentration recht empfindlich.

Um die Veröffentlichung nicht mit den Protokollen zu überladen, sei auf die Arbeit von Dresel und Freund verwiesen, wo sich auf S. $327 \mathrm{ff}$. ausführliche Protokolle finden, und zwar negative und positive. Hier sollen bei der großen Zahl der untersuchten Sera immer nur die Keimzahl der sofortigen Bouillonkontrolle und als zweite die niederste Keimzahl, welche durch die anthracociden Stoffe erzielt wurde, angegeben werden. Es bedeutet also die Schreibweise 1000/0, daß die Keimzahl in der Bouillonkontrolle sofort 1000 betrug, während in den Serumröhrchen, und zwar entweder sofort oder nach 1, 4 und 6 Stunden die Keimzahl auf 0 sank. In allen Fällen, in denen eine glatte Abtötung aller eingebrachten Keime nicht eintrat, ist als zweite Zahl die niedrigste Keimzahl der Serumagarplatten angegeben. Diese niedrigste Keimzahl fand sich in der Mehrzahl der Untersuchungen schon nach 1 oder 4 Stunden, nicht selten auch erst nach 6 Stunden. In diesen Fällen zeigte sich immer eine gleichmäßige Abnahme. Waren die bactericiden Kräfte des Serums schon nach 1 oder nach 4 Stunden erschöpft, ohne daß alle eingebrachten Milzbrandkeime a bgetötet waren, so tritt selbstverständlich in der Untersuchung der 4. oder 6. Stunde wieder eine Zunahme auf, die dann aber regelmäßig weit hinter dem Anwachsen der Keimzahlen in den Kontrollen zurückblieb. Ein solches Verhalten schwächerer Anthracocidie fand sich bei den Versuchen mit Normalserum niemals.

\section{Versuche mit Serum gesunder Menschen.}

Bei der Untersuchung des Serums von Männern mußte berücksichtigt werden, ob nicht etwa die Typhus- und Choleraschutzimpfung der Kriegszeit noch nachwirkte, trotzdem es ja durch die seitdem vergangene Zeit unwahrscheinlich war. Zur Untersuchung kamen die Sera von 12 klinisch völlig gesunden Männern, die auch längere Zeit vorher keinerlei Erkrankungen durchgemacht hatten. Geimpft waren davon im Kriege gegen Typhus und Cholera mit Sicherheit 7, sicher nicht geimpft 1, die übrigen konnten keine zuverlässigen Angaben machen. Im Serum dieser 12 Männer fanden sich keine oder nur geringe Spuren von anthracociden Stoffen. Ebenso verhielten sich die Sera von 5 jugendlichen Frauen. Da Dresel und Freund bei Kaninchen eine Steigerung der milzbrandtötenden Kräfte im Plasma durch Aderlässe festgestellt hatten und da inzwischen im Serum von Frauen während der Menses das Auftreten von milzbrandbacillentötenden Kräften sichergestellt war, mußte bei Serumproben von Frauen, die als normale 
gelten sollten, darauf geachtet werden, daß nicht nur Schutzimpfungen gegen Typhus und Cholera nicht vorausgegangen waren, sondern auch die Blutentnahme nicht mit der Menstruation zusammenfiel. 4 Frauen waren nicht geimpft, alle 5 befanden sich im Menstruationsintervall zwischen 2-10 Tagen vor der kommenden Menstruation. Alle 5 hatten keine oder nur ganz geringe anthracocide Kräfte im Blute.

Ergebnis: Klinisch gesunde Männer und Frauen, diese im Menstruationsintervall, haben im Serum keine oder nur geringe Spuren von anthracociden Kräften. Eine vor mindestens 3 Jahren vorausgegangene Schutzimpfung gegen Typhus und Choldra hat keinen Einfluß mehr auf die Bildung von milzbrandfeinlichen Kräften.

\section{Serum von Neugeborenen.}

Da wir in der vorigen Mitteilung festgestellt hatten, da $B$ Schwangerschaft in den letzten Wochen im Serum gesunder Frauen starke Anthracocidie hervorruft, interessierte es, Serum von Neugeborenen auf bakterienfeindliche Kräfte zu untersuchen. Die Serumproben verdanken wir der Frauenklinik; dort wurden die Blutproben beim Abnabeln aus der Nabelvene gewonnen. Untersucht wurden 22 Sera gegen Milzbrand und 16 davon auch gegen Typhusbacillen.

Die bactericide Kraft gegen Milzbrand war:

$600 / 0-600 / 0-600 / 0-580 / 0-580 / 10-580 / 52-580 / 0-$ $580 / 0-350 / 17-350 / 0-350 / 85-350 / 32-350 / 70-350 / 53-$ $260 / 0-152 / 0-152 / 6-152 / 1-190 / 0-350 / 18-350 / 81-350 / 0$.

Die bactericide Kraft gegen Typhus war:

$3000 / 0-3000 / 0-3000 / 25-3000 / 0-2500 / 0-2500 / 0-$ $2500 / 11-3000 / 0-3000 / 50-3000 / 0$, in 6 weiteren Fällen fand bei 3000 ausgesäten Keimen eine sehr starke Abnahme statt.

Ergebnis: Serum von Neugeborenen enthält große Mengen von bactericiden Stoffen gegen Milzbrand- und Typhusbacillen.

\section{Serum während der Menstruation.}

Zur Untersuchung kamen 14 Sera von klinisch völlig gesunden jugendlichen weiblichen Personen, und zwar 5 am 1., 5 am 2., 1 am 4., und 3 am 7. Tage der Menstruation.

Die bactericide Kraft gegen Milzbrandbacillen war:

1. Tag: 500/265 - 500/12 - 500/125 - 960/36 - 350/8; 2. Tag: 520/16 - 400/0 - 400/260 - 500/175 - 800/155; 4. Tag: 960/400; 7. Tag: $750 / 5-960 / 120-630 / 45$.

Die Sera von 2 Frauen konnten im Intervall 3 Tage vor den Menses nochmals untersucht werden und enthielten dann keine milzbrandfeindlichen. Stoffe. Die Ergebnisse bei diesen beiden während der Menses sind im Druck hervorgehoben. 
Ergebnis: Während der Menstruation enthält das Serum von klinisch gesunden Frauen große Mengen von milzbrandfeindlichen Kräften, die im Intervall kurz vor der Menstruation wieder verschwunden sind.

\section{Sera von klinisch kranken Menschen.}

Untersucht wurden 31 Fälle von verschiedenen fieberhaften akuten Infektionskrankheiten. Es ergaben Pneumonien: 4; 630/0 - 320/0 1200/0 - 950/170 (10 Tage nach der Entfieberung nur noch 1200/560); interlobuläres Exsudat: 1; 600/0; Grippe: 2; 500/0 - 750/0; außerdem konnten 3 Sera von Patienten untersucht werden, die eine schwere Grippe durchgemacht hatten. Nr. 1 ergab 4 Wochen nach der Genesung 960/0; Nr. 26 Wochen nach der Genesung 750/11; Nr. 3 1/4 Jahr nach der Genesung 960/500; Sepsis: 1: 630/0; 4 Patienten einer ungeklärten Saalepidemie, die wegen anderer geringer Beschwerden im Krankenhaus waren und plötzlich mit hohem Fieber bis 39,8 ganz akut für einige Tage erkrankten: 620/0 - 340/0 - 349/0 - 950/4. Scharlachfälle: $2 ; 500 / 60-1200 / 0$. Ein dritter Scharlachkranker hatte während der Schuppung nach der Entfieberung 860/80. Pyogene Dermatose: $1 ; 860 / 13$. Polyarthritis rheumatica: 1; 470/0. Erythema exsud. nach Gelenkrheumatismus: 1; 260/0; Arthritis gonorrhoica: 2; 880/0 - 1200/0; derselbe Patient nach Entfieberung 1200/0. Dazu noch ein Fall ohne Fieber: 340/80. Parametritis: 1; 740/0. Cystitis und Pyelitis: 7 ; 470/0 - 800/30 - 960/15 - 960/3 - 340/0 - 1000/0 und ein Kranker; dessen Serum 3 mal im Abstand nach 8 Tagen und 6 Wochen untersucht wurde: $600 / 0 ; 740 / 0 ; 340 / 0$. Entzündliche Prozesse nach Abort: 2; 800/0 - 314/0. (Diese 2 Fälle sind nicht eindeutig, ebenso wie der folgende, weil die Schwangerschaft mitsprechen könnte.) Im ersten Fall handelt es sich um einen künstlichen Abort im 3. Monat, im zweiten um einen Abort bei Placentarpolyp im 5. Monat. Beim nächsten Fall, einer fieberhalten Bronchitis, lag Schwangerschaft im 6. Monat vor: 1200/15. Eine Erkrankung an Pleuritis exsudativa fraglicher Ursache: 1200/0.

Ergebnis: 40 Sera von akuten fieberhaften Infektionskrankheiten weisen sehr starke milzbrandfeindliche Stoffe auf.

\section{Sera bei Erkrankungen an Tuberkulose.}

Bei 3 Erkrankungen an Tuberkulose, die klinisch und durch Röntgenbefund gesichertt waren, die aber keine erhöhten Temperaturen und im Auswurf keine Tuberkelbacillen hatten, bei denen es sich um cirrhotische Spitzen- und Oberlappenprozesse handelte, ergab die Serumuntersuchung: 269/10-800/600 und 860/880. Der erste Fall wies einen schlechten Allgemeinzustand auf bei geringem Hämoglobingehalt des Blutes und sekundär anämischen Erscheinungen, die wohl 
für das Vorhandensein der anthracociden Stoffe verantwortlich gemacht werden müssen.

Ergebnis: Bei alten fíeberlosen cirrhotischen tuberkulösen Prozessen der Lunge können anthracocide Kräfte fehlen oder in geringer Menge vorhanden sein.

Bei 7 Erkrankungen an Tuberkulose mit ganz geringen, meist morgendlichen Temperatursteigerungen von einigen $1 / 10$ Graden über $37^{\circ}$ mit sicherem Röntgenbefund, von denen 2 keine und 5 Tuberkelbacillen im Sputum hatten, ergab die Serumuntersuchung: 600/400 $340 / 160-1000 / 220-800 / 250-1200 / 770-800 / 4-500 / 1$. 5 von den 7 Personen waren Frauen, bei denen das Blut im Menstruationsintervall entnommen wurde. Die beiden letzten Fälle mit dem großen Ausschlag sind nicht ganz eindeutig. Bei dem vorletzten fand sich Blut im Stuhl, doch konnte die Frage der Darmtuberkulose oder des frischen Ulcus ventriculi nicht entschieden werden. Der letzte Kranke hatte 4 Wochen vor der Blutentnahme eine Hämoptoë gehabt.

Ergebnis: Offene und geschlossene mit geringen Temperatursteigerungen verlaufende tuberkulöse Lungenerkrankungen können eine beträchtliche Steigerung der anthracociden Kräfte im Serum hervorrufen.

Bei 11 Erkrankungen an Tuberkulose mit meist hochfieberhaften Temperaturen und positivem Tuberkelbacillenbefund in allen Fällen ergab die Serumuntersuchung: 1200/0 - 1200/6 - 260/0 - 470/0 $340 / 0-1200 / 0$ - 1200/14 - 800/0 - 560/0 - 500/0 - 1200/0. Darunter befinden sich 4 Frauen, deren Blut im Menstruationsintervall entnommen wurde.

Von diesen Erkrankten starben 3 innerhalb 1 Woche nach der Blutentnahme, 3 in einem Zeitraum bis zu $1 \frac{1}{2}$ Monaten. Es handelte sich in allen 11 Fällen um schwere ausgedehnte Tuberkulosen. Von den noch lebenden 5 hatten 4 auf die Lunge beschränkte Erkrankungen, 1 außerdem noch eine Peritonitis exsudativa tuberculosa. Bei den 6 Gestorbenen ergab die Sektion in einem Falle Lungen- und Kehlkopftuberkulose, I mal Lungen- und Darmtuberkulose, 1 mal Lungentuberkulose und allgemeine Sepsis, 1 mal Lungen-, allgemeine Drüsenund Genitaltuberkulose, 1 mal Lungen- und Bauchfelltuberkulose und 1 mal Lungen- und Miliartuberkulose.

Ergebnis: Serum von Menschen mit ausgedehnter Tuberkulose und hohem Fieber enthält sehr reichliche milzbrandbacillentötende Kräfte. Schlüsse auf Beziehungen zwischen milzbrandtötender Kraft des Serums und Ausdehnung bzw. Form der Erkrankung lassen sich bisher nicht ziehen.

\section{Sera von Luetikern.}

Bei 7 Erkrankungen an Lues ohne Fieber und ohne vorausgegangene antiluetische Behandlung ergab die Serumuntersuchung: 190/0 - 
$630 / 140$ - 1100/650 - 620/0 - 340/0 - 560/0 - 620/60. Bei allen 7 Fällen war die WaR. positiv. Es handelt sich um eine Encephalitis luetica, eine Lues larvata, eine Lues hereditaria, um eine luetische Drüsenerkrankung, einen frischen Infekt und 2 bisher nicht behandelte Patienten mit Herzerkrankungen. Bei 5 behandelten Fällen, davon 3 mit Quecksilber- und 2 mit Salvarsankuren, die teilweise jahrelang zurücklagen, ergab die Serumuntersuchung: 600/0 - 620/9 - 340/0 $-1600 / 600-620 / 120$. DieWaR. war in allen Fällen positiv. Bei 2 Fällen von Tabes dorsalis mit positivem Wassermann, von denen der erste 1914 und 1921 kombiniert behandelt ist, während der zweite $11 / 2$ Jahre krank und unbehandelt ist, ergab die Untersuchung: 2000/12 - 1000/5.

Besonders erwähnenswert sind 2 Fälle; der eine, der unbehandelt 1100/650 aufwies und 5 Wochen später nach einer beendigten Quecksilberkur im Serum 2 Stunden nach einer Salvarsaninjektion alle eingebrachten 620 Milzbrandkeime abtötete.

Ein weiterer Fall von Angina luica konnte 3 mal untersucht werden. Die WaR. war zweifelhaft. Die erste Serumprobe ergab 340/0, die zweite nach 10 Tagen 860/5, die dritte nach weiteren 14 Tagen 800/300. Zwischen der 2. und 3. Blutentnahme, 6 Tage vor der letzten Entnahme wurde $\mathbf{0 , 3}$ Neosalvarsan injiziert.

Ergebnis : Bei Lues, und zwar bei unbehandelter und behandelter, finden sich im Sèrum sehr große Mengen von milzbrandbacillentötenden Kräften, die anscheinend durch die Behandlung gesteigert oder vermindert werden zu können scheinen.

\section{Anämien.}

Die Serumuntersuchungen von 2 Kranken mit Anaemia perniciosa ergaben: 1000/0 - 1000/0; bei einer Leukämie 960/0; einer Pseudoleukämie 260/0. Bei 7 sekundären Anämien im Anschluß an ein Ulcus ventriculi ergab sich : 1000/0 - 800/220 - 960/240 - 750/2 - 751/1 630/0 - 340/0; bei einer im Anschluß an ein Ulcus duodeni 320/0. Bei 4 Carcinom-Kachexien ergab sich: $314 / 0-620 / 0-350 / 0-350 / 15$. Das Serum eines Falles von Beckentumor ergab 350/75; das eines Oberschenkelsarkoms 350/7. In einem Fall von Morbus Banti ergab sich : $260 / 70$.

Ergebnis: Bei Anämien und sekundären Anämien findet sich starke Anthracocidie.

\section{Rheumatische Erkrankungen.}

In 3 Fällen von Gelenkrheumatismus mit Salicyltherapie ergab sich im Serum: $2000 / 0-630 / 1-630 / 1$, in 2 Fällen ohne Therapie: $190 / 0$ und $340 / 0$.

Ergebnis: Bei rheumatischen Gelenkentzündungen findet sich mit und ohne Salicyltherapie starke Anthracocidie. 


\section{Lebererkrankungen.}

Untersucht wurden 7 Fälle von Lebererkrankungen mit folgendem Ergebnis: Cirrhosis hepatis: 1; 460/0; Ikterus bei Dystrophia adiposogenitalis: 1 ; 340/7; Cholangitis: 1; 560/0; Cholecystitis: 1 ; 314/2; Cholelithiasis: 3 ; 340/0 - 560/10 - 325/65.

Ergebnis: Bei Lebererkrankungen treten anthracocide Stoffe im Serum auf.

\section{Chronische Nierenleiden.}

Drei Sera bei chronischen Nephritiden ergaben: 1000/0 - 1600/700 - 960/300. Ein Fall von Urämie konnte 4 mal untersucht werden. Bei der ersten Blutentnahme ergab sich 880/26; 5 Tage später 900/23; nach 5 weiteren Tagen 1100/1060, nach weiteren 3 Tagen 960/0. Worauf der fast negative Befund bei der 3. Blutentnahme zứrïckzuführen ist, läßt sich nicht sicher entscheiden. Vielleicht müssen die beiden vorausgegangenen großen Aderlässe dafür verantwortlich gemacht werden, doch dann würde das Auftreten der starken Anthracocidie nach weiteren 3 Tagen unerklärlich sein.

Ergebnis: Bei chronischen Nierenleiden treten Anthracocidine auf.

\section{Chronische Herz- und Gefäßerkrankungen.}

Die Untersuchung des Serums in einem Falle von Mitralinsuffizienz mit Stenose ergab 400/75; in einem Fall von kompensiertem Vitium cordis bei einem im Kriege erlittenen Lungenschuß 1000/28; bei einem Fall von Hypertonie mit Atherosklerose 1000/1; bei Herzbeutelbeschwerden mit subfebrilen Temperaturen $960 / 226$; in 2 Fällen von Atherosklerose mit negativem Wassermann 190/0 - 2000/7; bei einem Fall von Apoplexie mit Mitralstenose und negativem Wassermann 560/200; bei einem Fall von Dysbasia angioselerotica 740/45; bei einem Fall von schwerem Nicotinmißbrauch und Nicotinvergiftung 340/28.

Ergebnis: Bei chronischen Herz- und Gefäßerkrankungen treten reichliche milzbrandbacillentötende Stoffe auf.

\section{Chronische Erkrankungen.}

Die Untersuchung des Serums ergab in einem Fall von chronischer Bronchitis 560/30; bei einer chronischen Dysenterie mit Rectalgeschwïren 1000/0; bei einer anderen 630/22; in einem Falle von jahrelangen Kreuzschmerzen nach Verheben 152/0; bei einer Querschnittsmyelitis nach Panaritium 520/3; bei eine Spondylitis traumatica 1600/112; bei zwei paravertebralen Abscessen 620/20 - 560/15; bei einer Epididymitis gonorrh. $750 / 336$.

Ergebnis: Bei chronischen entzündlichen Prozessen treten Anthracocidine in erheblichen Mengen auf. 


\section{Konstitutionelle Erkrankungen.}

Die Serumuntersuchung ergab in einem Falle von Diabetes mellitus mit chronischer Neuritis und Gingivitis 470/0; in einem Falle von Dystrophia adiposogenitalis $740 / 0$; in einem Falle von Thyreoidismus 1000/140; in einem Falle von konstitutionellem Ekzem mit Eosinophilie 560/350; bei einem Falle von Jacksonepilepsie 1000/260.

Ergebnis: Bei verschiedenen konstitutionellen Erkrankungen ließen sich im Serum mittelstarke bis starke Mengen von milzbrandbacillenfeindlichen Kräften nachweisen.

\section{Verschiedene Erkrankungen.}

Die Serumuntersuchung orgab bei einer Erkrankung an chronischer Cephalaea $320 / 60$, bei einer an chronischer Malaria mit Pleocytose und Dilatatio cordis $1000 / 690$, bei einer chronischen Ischias unter Chinintherapie 880/155; bei einer Gastroptose 1000/21. Dazu kommen noch 3 Erkrankungen an Neurasthenie; der erste hatte eine Schockreaktion mit leicht erhöhten Temperaturen, die WaR. war negativ: 630/80; der zweite war ein starker Raucher und litt an chronischen Anginen: 560/1; bei dem dritten war kein Befund zu erheben, ihm war am Tage zuvor der Magen ausgehebert: 1000/660.

Außerdem wiesen noch die Sera von 3 klinisch gesunden Menschen starke milzbrandbacillenfeindliche Stoffe auf. Es handelt sich um einen Arzt mit im Kriege amputiertem Oberschenkel bei umfangreicher Muskelzertrümmerung am Stumpfe: 750/5; um einen Mann, der im Kriege einen schweren Lungenschuß erlitt und vor einem Jahre eine Magen- und Appendixoperation durchmachte: 2000/4; um eine Ärztin (im Menstruationsintervall), der vor einem 1/2 Jahre mehrere große Aderlïsse zu wissenschaftlichen Untersuchungen gemacht waren: $960 / 175$.

\section{Verschwinden der Anthracocidie.}

Die durch irgendeinen Reiz, wie akute oder chronische Infektion mit und ohne Fieber, oder Blutung, oder Schwangerschaft, oder degenerative und narbige Prozesse ausgelöste Anthracocidie scheint nach Abklingen des Reizes zu verschwinden.

Eine unklare fieberhafte Infektion mit Fieber bis über $39^{\circ}$ tötete auf der Höhe des Fiebers die in das Serum eingebrachten Milzbrandbacillen restlos ab, dagegen 14 Tage nach der Entfieberung blieben von 1200 eingebrachten Milzbrandkeimen 260 am Leben. Bei eincr Lungenentzündung, die auf der Höhe des Fiebers von 950 Keimen 170 nicht abtötete, blieben nach der Entfieberung von 1200 Keimen 506 am Leben.

Andererseits scheint ein zu starker Reiz durch Häufung von Krankheitsprozessen im Körper oder durch therapeutische Einwirkung die erwartete Anthracocidie nicht mehr auszulösen. 
Im Serum einer perniziösen Anämie mit 2780000 roten und 5000 weißen Blutkörperchen, die s. it 2 Monaten mit Elektroferrol und in den letzten 2 Wochen vor der Blutentnahme täglich mit 3 mal 0,05 Arsacetin behandelt war, fand sich überhaupt keine Anthracocidie.

Im Serum einer Patientin mit chronischer Lungentuberkulose, Cholecystitis und Cholelithiasis, deren Blut während der Periodo entnommen wurde, wurden von 800 eingebrachten Milz.brandkeimen nur 100 abgetötet.

Das Surum einer schweren Urämie mit Retinitis enthielt keine anthracociden Stoffe.

Bei einer Patientin mit angeborener Lues und chronischer Arthritis bei Salicyltherapie im 9. Schwangerschaftsmonat blieben von 1200 eingebrachten Milzbrandkeimen im Serum 900 am Leben.

Im Serum einer Angina luica ergab sich folgender Befund: Das Serum der unbehandelten Patientin tötete 340 Milzbrandbacillen ab. 10 Tage später blieben von 860 eingebrachten Milzbrandbacillen 5 am Leben, nach weiteren 14 Tagen, 6 Tage nach einer Salvarsaninjektion von 0,3 , blieben von 860 eingebrachten Milzbrandkeimen 300 am Leben.

Das Serum einer Frau mit schwerem Diabetes mellitus $(4,3 \%$ Sacch. Aceton und Acetessigsäure ++), das am zweiten Tage der Menses entnommen wurde, zeigte keine Anthracocidie.

Verhalien des Serums gegen Milzbrand- und Typhusbacillen.

Weiterhin sollte die Frage beantwortet werden, ob die bakterientötenden Kräfte im Serum von Gesunden und Kranken außer Milz. brandbacillen auch andere Bakterienarten abtöten.

Untersucht wurden 50 Sera gleichzeitig auf Bactericidie gegen Milzbrand- und Typhusbacillen. Darunter waren die Sera von 5 wiederholt während des Krieges mit Typhusschutzimpfstoff geimpften und von 8 nicht geimpften Männern, 21 Sera stammten von Frauen, und zwar 9 von noch nicht oder nicht mehr menstruierten, während die übrigen I2 alle am ersten oder zweiten Tage der Menstruation waren. Von diesen 12 Seren stammten 7 von klinisch völlig gesunden Frauen. Die übrigen 27 Personen waren wegen klinischer Befunde bettlägerig krank. Alle Sera wiesen starke abtötende Stoffe gegen Milzbrand auf. 19 töteten die eingebrachten Milzbrandbacillen restlos ab. 32 Sera töteten die in der Aussaatmenge zwischen 1600 und 6000 schwankenden Typhusbacillen $a b$, bei zweien zeigte sich eine sehr starke Verminderung der eingebrachten Typhusbacillen.

In 16 Fällen konnte Nabelvenenblutserum von Neugeborenen gegen Milzbrand- und Typhusbacillen geprüft werden. Ebenso wie die Milzbrandbacillen wurden in 7 Fallen die eingebrachten 3000 Typhusbacillex restlos abgetötet, in 3 Fällen blieben je 11, 25 und 50 Typhus- 
keime am Leben, in 6 Fällen fand eine sehr starke Verminderung der Zahl der Typhusbacillen statt.

Es wäre verlockend, dieses Ergebnis mit anderen Tatsachen in Beziehung zu setzen, die bisher bei unspezifischen Reizwirkungen in den Körpersäften durch biologische, physikalische und chemische Untersuchungsmethoden festgestellt sind. Doch halten wir es für notwendig, ehe an die bisherigen Ergebnisse Hypothesen angeknüpft werden, die wir uns für später vorbehalten, weitere Tatsachen zu sammeln.

\section{Zusammenfassung.}

Im Serum klinisch gesunder Männer und bei klinisch gesunden Frauen im Menstruationsintervall finden sich keine Anthracocidine.

Das Serum klinisch gesunder Frauen enthält während der Men. struation bactericide Stoffe gegen Milzbrandbacillen, die nach 14 Tagen wieder verschwunden sind.

Im Nabelvenenblut gesunder Neugeborener finden sich Bactericidine gegen Milzbrand- und Typhusbacillen.

Sera von klinisch kranken Menschen enthalten sehr reichliche Anthracocidine, und zwar bei fieberhaft akuten und chronischen Infektionskrankheiten; bei Infektionskrankheiten ohne Fieber (chronische Tuberkulose, Lues, Rheumatismus); bei Bluterkrankungen; bei chro: nischen Krankheiten mit Organveränderungen, wie Lebererkrankungen, Herz- und Gefäßerkrankungen und chronischen Nierenérkrankungen; bei schweren Verletzungen und Operationen mit schweren Vernarbungsprozessen.

Die Therapie kann die Bildung von Anthracocidinen steigern, sie kann sie jedoch bei zu großen Dosen zum Verschwinden bringen. Ebenso scheint das Zusammentreffen von verschiedenen schweren Organerkrankungen zu wirken (Arndt-Schulzsches Gesetz?).

50 Sera töteten Milzbrand- und Typhusbacillen ab.

\section{Literaturverzeichnis.}

1) Dresel, $E$. G. und $H$. Freund, Studien zur unspezifischen Reiztherapie. 2. Mitt. U̇ber die experimentelle Steigerung der Anthracocidie im Blute. Arch. f. exp. Pathol. u. Pharmakol. 91, H. 6. $\left.-{ }^{2}\right)$ Pfeiler, Otto, Über den Einfluß intravenöser Proteir körperzufuhr auf die Bactericidie des Normalserums. Dr: Dissertation. München 1922. R. Oldenbourg. 